\title{
Web sites governamentais, uma esplanada à parte*
}

\section{Elza Maria Ferraz Barboza}

PhD em ciência da informação pela Universidade de Brasília e tecnologista sênior da Gerência de Novas Tecnologias do IBICT.

E-mail: elza@ibict.br

Eny Marcelino de Almeida Nunes

Msc em ciência da informação pela Universidade de Brasília e tecnologista sênior da Coordenação de Infra-estrutura, Informática e Redes do IBICT.

E-mail: eny@ibict.br

\section{Nathália Kneipp Sena}

Jornalista e analista em ciência e tecnologia da Gerência de Novas Tecnologias do IBICT.

E-mail: nathalia@ibict.br

\section{Resumo}

Análise e avaliação de web sites do governo federal brasileiro, especificamente dos ministérios pertencentes aos setores constantes do programa Sociedade da Informação. O trabalho foi realizado mediante aplicação de lista de critérios e recomendações ergonômicas. Os critérios foram agrupados em quatro grandes quesitos: abrangência e propósito, conteúdo, planejamento visual/gráfico e funcionalidade. Concluiu-se que, com relação aos critérios adotados neste trabalho, os sites dos órgãos governamentais devem procurar maior adequação às recomendações ergonômicas.

\section{Palavras-chave}

Web sites; Avaliação; Usabilidade; Governo; Brasil.

\section{Governmental web sites, a virtual esplanade}

\begin{abstract}
Web sites of Brazilian federal government were analysed and evaluated, particularly the sites of the ministries that are part of the Information Society Programme. A checklist based on ergonomic principles was established. Evaluative criteria were clustered into four large main headings: scope and purpose; content; graphics and multimedia design; workability. It points out that the governamental agencies should improve their web sites aimed at a better adequacy to ergonomic standards.
\end{abstract}

\section{Keywords}

Web sites; Evaluation; Usability; Government; Brazil.

Artigo aceito para publicação em 24/04/2000

\section{INTRODUÇÃO}

"De um traço nasce a arquitetura", filosofa Oscar Niemeyer, parceiro de Lúcio Costa na concepção da Esplanada dos Ministérios e da Praça dos Três Poderes, ambas cartões postais da capital federal. Com o aparecimento do primeiro site brasileiro em 1993 e, subseqüente, boom da Internet, instalou-se um novo canteiro de obras no planalto central, espaço propício para o surgimento de uma esplanada digital, erguida por arquitetos anônimos. Enquanto a primeira permanece intocada como patrimônio da humanidade, a segunda é mutatis mutandis. Trazendo os dizeres de Niemeyer para a era dos bytes, admite-se que, de um pensamento afeito à ergonomia, nasça a arquitetura de um web site, competindo a uma equipe multidisciplinar a responsabilidade de alçálo à excelência em sua qualidade, favorecendo a coleta, reprodução, indexação e disseminação de informações, de forma acurada, para um público extremamente diverso.

Estima-se que o ano 2000 terminará com 1 bilhão de pessoas conectadas à Internet ${ }^{* *}$. O setor de Tecnologia da Informação (TI) gerou 2\% do PIB brasileiro em 1998, o que se traduz em US\$ 17 bilhões***. Em 1999, segundo pesquisa realizada pela agência internacional de comunicações Nazca Saatchi \& Saatchi ${ }^{* * * *}$, a média da América Latina era de um internauta a cada 52 habitantes e, no Brasil, de uma pessoa a cada grupo de 34. Com o aparecimento de um público diversificado e numeroso para as páginas da Web, as questões referentes à infra-estrutura da rede começam a partilhar o centro das atenções com as análises pertinentes ao universo das aplicações das novas tecnologias de informação. O que e como fazer para desenvolver uma nova geração de redes Internet que traga benefícios a toda a sociedade brasileira?

\footnotetext{
* Síntese do trabalho elaborado para o programa "Sociedade da Informação", intitulado Análise dos web sites governamentais, Brasília, IBICT/SocInfo, novembro de 1999.

${ }^{* *}$ Previsão de Nicholas Negroponte, fundador e diretor do Media Lab do Massachusetts Institute of Technology (MIT), em seminário realizado na Expo Management 99, em Buenos Aires.

*** "O Fenômeno Internet no Brasil - dados para reflexão". Encarte especial Brasil.com, de 3 de novembro de 1999, da Revista Exame.

**** "Internet faz sucesso no Chile", Correio Braziliense, 20 de novembro de 1999.
} 
Numa pesquisa por amostragem o IBOPE* ouviu $15 \mathrm{mil}$ pessoas nas nove maiores capitais do Brasil e concluiu que o número de internautas no país cresceu $36 \%$ entre dezembro de 1999 e fevereiro de 2000, ou seja, de 3,3 para 4,5 milhões de pessoas conectadas. Mas, dos 5.507 municípios brasileiros, apenas 350 dispõem do serviço de acesso à rede. Para os 5.157 restantes a Internet ainda faz parte do imaginário.

O desenvolvimento e o uso difundido das tecnologias de informação e comunicação vêm afetando o setor público que procura absorver e usufruir os benefícios que essas tecnologias oferecem para melhorar sua atuação junto às empresas.

O presente trabalho centra-se na análise do conteúdo e da forma de apresentação de uma parcela das home pages dos sites do governo federal brasileiro, sob o ponto de vista de suas características ergonômicas, ou seja, a usabilidade que elas oferecem aos usuários (ver quadro, "Usabilidade"). Foram privilegiados os setores incluidos pelo Grupo de Trabalho sobre Sociedade da Informação, no âmbito do Conselho Nacional de Ciência e Tecnologia (CCT/MCT). Esse grupo produziu o documento "Ciência e Tecnologia para a Construção da Sociedade da Informação no Brasil", ideário que norteia as políticas governamentais estabelecidas para o setor.

Apresentar um levantamento detalhado sobre a usabilidade dos sites governamentais, analisando-os sob o ponto de vista dos preceitos da ergonomia e da apresentação de seus conteúdos, é um quesito indispensável para a compreensão dos elementos que hoje beneficiam ou desfavorecem a comunicação entre o governo e os cidadãos brasileiros, assim como da imagem ou cartão de visitas que o Brasil mantém perante as nações que compartilham o ciberespaço.

O que foi encontrado nos web sites governamentais é digno de cumprimentos, mas também de ponderações e proposições de mudanças. Sob o aspecto da ergonomia, apresentam deficiências muitas vezes primárias, as quais procuramos evidenciar com uma análise individualizada de cada site ministerial. Mediante uma tabela de critérios - os quais também podem ser lidos como sugestões enumeramos os pontos fracos e fortes de cada um, cientes dos limites impostos pelas subjetividades e idiossincrasias inerentes a esse procedimento de análise, o qual coloca, sob uma lupa, essa mídia que, com muita agilidade e rapidez, implode postulados.

\section{USABILIDADE}

Usabilidade (usability) é "a extensão em que um produto pode ser usado por usuários específicos para alcançar objetivos específicos com eficácia, eficiência e satisfação num contexto específico de uso".

Quando um produto é avaliado na sua usabilidade, a ênfase é dada à sua otimização. Por não ter uma usabilidade intrínseca, só pode ser analisado com relação a seu uso dentro de um contexto específico. No entanto, existem três maneiras de se medir de forma direta a sua usabilidade:

1) pela análise de suas características requeridas num contexto específico de uso;

2) pela análise do processo de interação;

3) pela análise da eficácia e eficiência que resulta do uso de um produto.

É preciso, portanto, identificar os objetivos, e decompor a usabilidade (eficácia, eficiência e satisfação) em atributos passíveis de serem verificados e mensurados, assim como o contexto de uso (usuário, tarefa, equipamento e ambiente), conforme estrutura apresentada no quadro abaixo:

\section{Estrutura de usabilidade}

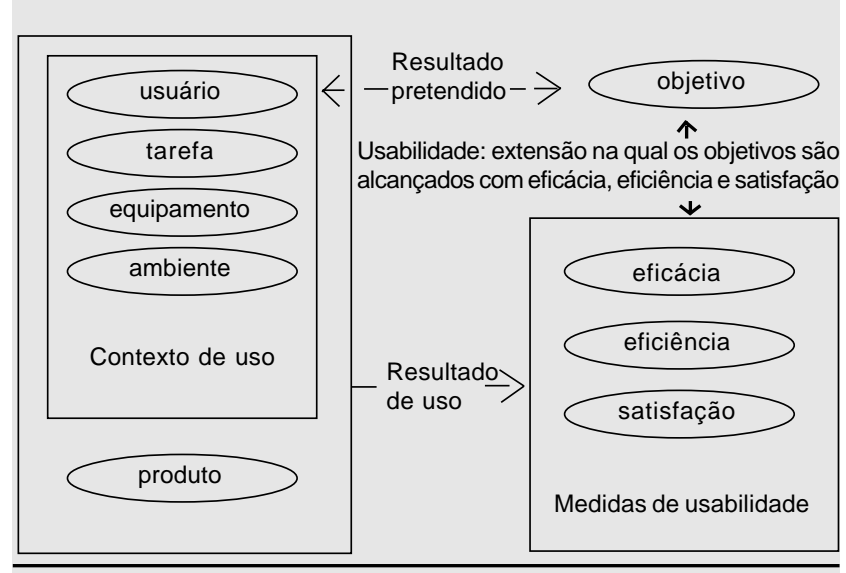

Fonte: ISO 9241. Ergonomic requirements for office work with visual display terminals (VDTs) - Part 11: Guidance on usability. (ISO 924111:1998). 
Para o Instituto Brasileiro de Informação em Ciência e Tecnologia, vislumbra-se a abertura de um novo domínio de atuação em que devem agrupar-se os profissionais das áreas de análise de informação e funções correspondentes às engenharias da Internet, profissões que detêm, hoje, uma nomenclatura diversificada. Para os governos, no campo de construção dos seus web sites, os estudos de usabilidade tornam-se indispensáveis para a estruturação de sua presença na rede e para garantir eficiência, eficácia e satisfação no processo de comunicação com os cidadãos, atingindo os objetivos inerentes a cada área de atuação do setor público.

\section{Do estabelecimento dos critérios de avaliação}

Foram selecionados nove web sites de ministérios, órgãos do primeiro escalão do governo federal, que têm como objetivo, oferecer serviços de informação para o cidadão, sem deixar despercebidas as ações programadas desse governo, encontradas no site do Avança Brasil. Os ministérios pertencem aos setores mencionados no escopo do projeto Sociedade da Informação, do MCT.

$\mathrm{Na}$ avaliação, foram levadas em consideração duas premissas importantes: identificar qual o tipo de página web a que pertenciam os sites e os critérios de qualidade, que seriam definidos de acordo com seus objetivos e metas.

Segundo tipologia de Tate \& Alexander e do Institute of Technology Assessment, os sites governamentais classificam-se como "prestadores de informação", encontrando-se disponibilizados no domínio .gov, e como "serviços de informação", respectivamente.

Foi adotada a abordagem analítica, realizada sem a presença do usuário. Especialistas se reuniram, em número de três (ergonomia, qualidade, comunicação), para examinar as interfaces criadas pelos ministérios selecionados e aplicar a lista de critérios definidos para avaliação de sites.

Para medir o nível de qualidade dos web sites, adotou-se parâmetro quantitativo, marcando-se os itens em colunas $\mathrm{S}$ (sim) ou N (não), onde o $\mathrm{S}$ foi interpretado como estar em conformidade com os critérios estabelecidos e o $\mathrm{N}$ como não estar em conformidade com aqueles critérios. Somou-se cada coluna, obtendo-se a pontuação para cada site.

Os equipamentos utilizados para a avaliação dos web sites foram:

1) um computador Pentium 200 MHZ, 32 MB de RAM, disco rígido de 4 GB e CD-ROM 8x;
A ISO 9241 é uma norma internacional que trata dos aspectos ergonômicos de hardware e de software no uso de terminais de vídeo. Tendo como título geral Ergonomic requirements for office work with visual display terminals (VDTs) ela é formada pelas seguintes partes:

Parte 1: Introdução geral

Parte 2: Condução associada aos requisitos da tabela

Parte 3: Requisitos para vídeo

Parte 4: Requisitos para teclado

Parte 5: Disposição do ambiente de trabalho e requisitos de postura

Parte 6: Requisitos ambientais

Parte 7: Requisitos para vídeo com reflexo

Parte 8: Requisitos para vídeo colorido

Parte 9: Requisitos para dispositivos de entrada, exceto teclado

Parte 10: Princípios de diálogo

Parte 11: Orientação na especificação de usabilidade e medidas

Parte 12: Apresentação da informação

Parte 13: Orientação ao usuário

Parte 14: Diálogos por meio de menu

Parte 15: Diálogos por meio de comando

Parte 16: Diálogos por meio de manipulação direta

Parte 17: Diálogos por meio de preenchimento de formulário

2) um computador 486, $32 \mathrm{MB}$ de RAM, disco rígido de 4 GB.

Para embasamento teórico, foram consultados os trabalhos de Ben Shneiderman, Jakob Nielsen, Alastair G. Smith, bem como normas de instituições como IBM, ISO - Norma 9241, partes 10, 11, 12 (ver quadro "ISO 9241") e Universidade de Yale, verificando-se, no entanto, que estavam voltados para criação de sites de uma forma geral, não estando direcionados para um determinado tipo de página, à exceção de Smith, que apresentou uma lista de itens direcionados para sites informacionais. Foi elaborada então um lista específica de critérios e recomendações ergonômicas para avaliação de páginas informacionais do governo federal brasileiro que ofereciam: 
- informações institucionais;

- prestações de serviços de download de interesse do usuário;

- prestação de serviços públicos em tempo real e de forma interativa com o cidadão.

Observou-se que as listas de critérios elaboradas por diversos autores eram resultantes da inclusão/exclusão de itens que faziam parte também de outras listas. Assim sendo, a composição do elenco de critérios para avaliação dos sites governamentais foi feita da mesma forma, fazendo-se as adaptações julgadas necessárias para esse tipo de página incluindo alguns itens relacionados especificamente ao governo brasileiro.

Foram adotados quatro dos sete quesitos apresentados no roteiro elaborado por Smith para sites informacionais: abrangência e propósito, conteúdo, planejamento visual/ gráfico (webdesign), funcionalidade (interface e quesitos de navegação), observando-se nos subitens a sua adequação ou não ao tipo de site em questão.

Abrangência e propósito: verifica a amplitude ou limitação da fonte de informação, sua profundidade e nível de detalhe, alguma restrição com relação à informação durante certos períodos; se a página atingiu seus objetivos ao expor os tópicos escolhidos, não deixando de mencionar informações significantes.

- A missão institucional está claramente enunciada na primeira página.

- Há títulos destacando os programas, serviços e produtos do ministério.

- Constam informações úteis para o exercício da cidadania conforme a área de atuação do ministério.

Conteúdo: avalia a apresentação da informação com relação à sua correção gramatical e ortográfica, aos erros de digitação, à qualidade de sua escrita e à clareza da comunicação de seu conteúdo facilitando a leitura; se está explícita a organização que produziu a página; se quem a produziu tem formação e/ou experiência na área; se consta no site a data de atualização; se a sua informação é exclusiva em termos de disponibilidade em outros formatos ou em outros sites; se existem links para outras fontes de informação.

- A menção das fontes da informação apresentada é um procedimento padrão.
- Existe um índice do conteúdo do site.

- Possui um link para as perguntas e respostas mais freqüentes submetidas ao ministério - FAQ (Frequently Asked Questions).

- O texto é de boa qualidade e tem estilo adequado à sintaxe do hipertexto.

- Faz-se referência ao editor, redator ou responsável pela elaboração dos conteúdos.

- Consta o endereço eletrônico do webmaster.

- Consta o endereço postal, número de telefone e fax do ministério.

- As páginas estão datadas, indicando a freqüência das atualizações.

- Existem links para outras fontes de informação sobre os assuntos abordados.

- O conteúdo reflete as parcerias estabelecidas entre os ministérios, anunciando campanhas/ações comuns.

- Contextualiza as iniciativas no âmbito do programa Avança Brasil.

- São profissionais das áreas de Informação e/ou Comunicação que elaboram o conteúdo.

Planejamento visual/gráfico (webdesign): verifica se as letras e os tipos estão claros, simples e facilmente legíveis; seu tamanho ou corpo está relacionado com a superfície que ocupa; sua disposição dá o destaque de acordo com o interesse dos títulos, e em contraste e harmonia com os espaços destinados a brancos e imagens; se os ícones representam claramente o que pretendem e se algum conteúdo de multimídia está incorporado de forma apropriada.

- A página tem um desenho harmônico que causa uma boa impressão à primeira vista.

- O número e tipo de cores usados revelam atenção dada às recomendações da Ergonomia.

- As fontes dos textos revelam atenção dada às recomendações da ergonomia.

- A logomarca do governo federal está incluída.

- A logomarca do ministério aparece nas páginas. 
- Utiliza-se frame lateral/de cabeçalho/de rodapé que auxilia a discernir como o site foi indexado.

- $\mathrm{O}$ uso de imagens contribui para facilitar a leitura.

- Os ícones têm uma relação com o conteúdo.

- Há fotografias que veiculam uma informação.

- Recursos de multimídia são usados em sintonia com os objetivos do site.

- Evita-se o uso de banners e/ou imagens que piscam ou se alternam, com o intuito de fazer marketing ou anunciar um conteúdo.

- As dimensões das áreas de textos e de imagens foram concebidas de forma a alcançar boa visualização nos diferentes tamanhos de tela.

- Foi um programador visual ou webdesigner que fez o projeto gráfico da página.

Funcionalidade (interface e quesitos de navegabilidade): se os aspectos relativos à navegação pelo site são bem objetivos, tais como o design do menu e a legibilidade da tela facilitando a navegação; se o "motor de busca" para recuperação da informação contém interfaces amigáveis e indexação da fonte como um todo; se as características de seus formatos são sempre funcionais, têm resultados e agregam valor ao site; se suas páginas carregam rapidamente ou se existe um espelho de site alternativo.

- O tamanho total dos arquivos de imagens utilizados na página é inferior a $100 \mathrm{~K}$, favorecendo a velocidade de carregamento da página.

- Mantém sempre um link de retorno para a primeira página.

- Navega-se bem no site, seja com um computador de última geração, seja com uma máquina que o acessa a 2.000 bits por segundo (bps).

- Há um mecanismo de busca.

- Há um mapa do site.

- A forma de indexação do menu da página inicial facilita o encaminhamento do usuário aos diversos conteúdos do site.

- Existe espaço para a interatividade com o usuário, seja com identificação do perfil dos visitantes ou coleta de informações por intermédio de formulários.

- Os documentos disseminados pelo ministério estão disponíveis para se fazer a transferência de arquivos.
- A URL é textual, e existe uma relação entre as palavras ou siglas usadas e o nome da instituição.

- Na redação do HTML, existem meta tags, fornecendo a descrição e as palavras-chave do site para os robôs dos sites de busca.

- O webmaster é um profissional da área de informática ou tecnologia da informação.

Os últimos itens dos quesitos Conteúdo, Planejamento visual/gráfico e Funcionalidade (números 15, 28 e 29 no anexo 1), apesar de serem julgados importantes, por estarem relacionados aos tipos de profissionais envolvidos na elaboração dos sites, não foram avaliados nesta etapa do trabalho.

\section{Do resultado da análise dos web sites governamentais}

Depois do preenchimento dos formulários de avaliação, foi feita uma análise detalhada em cada site, reunindo-se em uma tabela os resultados de todos eles (anexo 1).

Foi observado que o site que teve maior percentual de respostas em conformidade com os critérios estabelecidos foi o do ministério B $(72,2 \%)$, contra o resultado do ministério $\mathrm{H}$, cujas discrepâncias atingiram um percentual maior $(55 \%)$ do que as conformidades, conforme demonstrado na figura 1 .

\section{FIGURA 1}

Demonstrativo dos valores obtidos por ministério

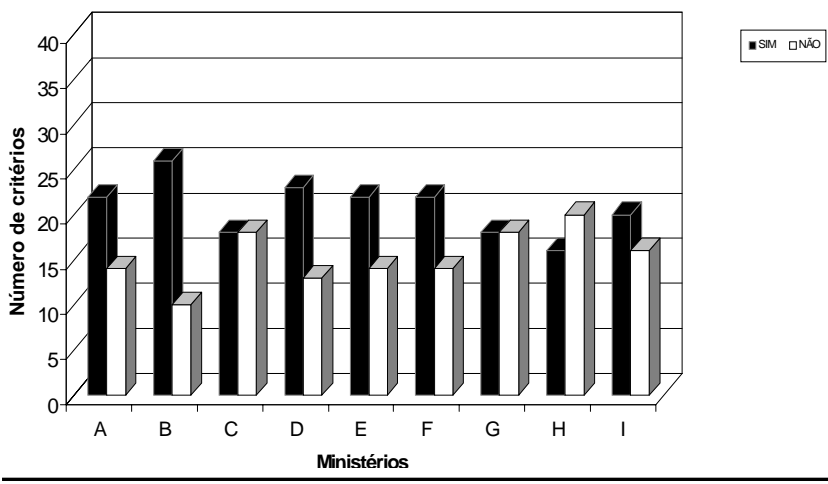

Quatro deles, além do ministério B, tiveram maior percentual de itens compatíveis com os critérios:

Ministério $\mathrm{A}=61,1 \%$

Ministério $\mathrm{D}=63,9 \%$

Ministério $\mathrm{E}=61,1 \%$

Ministério $\mathrm{F}=61,1 \%$ 
Os ministérios $\mathrm{C}$ e $\mathrm{G}$ preencheram positivamente $50 \%$ das exigências, e o ministério $\mathrm{H}$, apenas $44,4 \%$, ou seja, menos da metade das exigências estabelecidas nos critérios. Tais resultados encontram-se demonstrados também na figura 2.

No quesito "Abrangência e Propósito", os sites não incluíram as missões dos ministérios, item considerado importante porque dá ao usuário uma noção sobre a área de atuação da instituição. Todos destacaram seus programas, serviços e produtos, disponibilizando aos usuários informações úteis para o exercício de sua cidadania.

Quanto ao quesito "Conteúdo", alguns dos subitens não foram preenchidos satisfatoriamente, como pode ser verificado no anexo 1.

Ficou demonstrado que não é procedimento padrão a menção às fontes de informação e a menção ao nome do responsável pela elaboração dos conteúdos. Além de não datarem as páginas, não indicam as datas das atualizações. É importante que, além do endereço do Webmaster, conste o endereço postal, o telefone e o fax, dando oportunidade ao usuário de estabelecer contato com o ministério, se assim o desejar.

O site do ministério A foi o que obteve melhor resultado na análise do conteúdo $(72,7 \%)$ e o do ministério I, o resultado menos satisfatório $(36,4 \%)$.

No quesito "Planejamento visual", o melhor resultado foi obtido pelos Ministérios B e D, ambos com 83,3\%, seguidos pelo ministério E com um percentual positivo de $75 \%$. $\mathrm{O}$ site do ministério $\mathrm{G}$ foi o que apresentou uma performance menos satisfatória $(41,7 \%)$ nesse item.

O quesito "Funcionalidade" teve como melhor desempenho o ministério B com $80 \%$ de adequação aos critérios. $\mathrm{O}$ site que apresentou um desempenho menos desejável foi o do ministério $\mathrm{H}$ com apenas 20\% nesse quesito.

Dos nove ministérios, oito deles necessitam de revisão mais acurada no que tange ao quesito "Conteúdo". Quatro deverão dar maior atenção ao "Planejamento visual".

Segundo a ISO 9241, a interação entre o usuário e o sistema de recuperação de informação alcançará seu objetivo específico, utilizando-se princípios ergonômicos gerais, a seguir discriminados, quando se for projetar uma interface em terminal de vídeo:
FIGURA 2

\section{Comparação dos resultados obtidos por ministério}

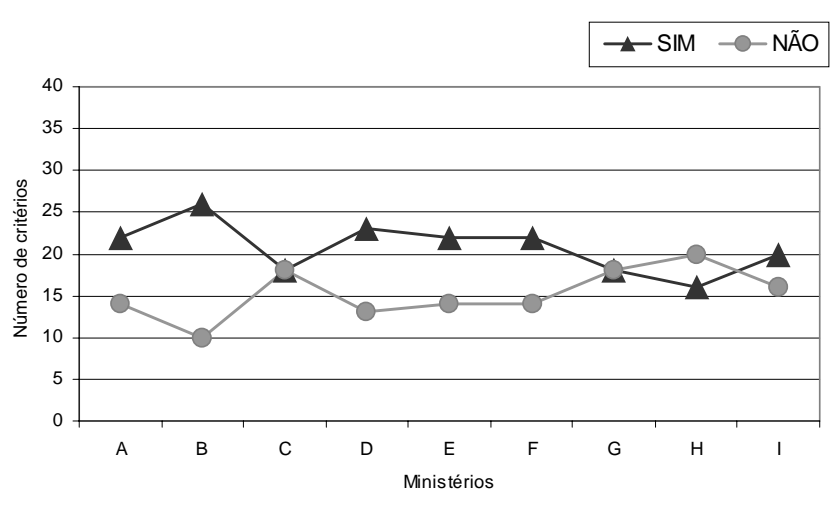

- ser adequada para a tarefa para qual foi determinado;

- ser autodescritiva;

- ter controlabilidade;

- estar em conformidade/atender com as expectativas do usuário;

- ter tolerância de erro;

- atender às individualidades;

- propiciar o aprendizado.

A interface poderá ser melhorada pela sua adaptação às práticas de design de diálogo, e pela interação entre o usuário e o restante do contexto de uso, obtida por meios tais como seleção e treinamento.

Para que o usuário venha a executar as tarefas com eficácia, eficiência e satisfação, é de suma importância que as características clareza, discriminabilidade, concisão, consistência, detectabilidade, legibilidade e compreensibilidade sejam levadas em consideração ao se projetar a informação visual.

O produto deve ter atributos que facilitem o aprendizado. O real aprendizado em um contexto específico pode ser medido mediante comparação da usabilidade de um produto para um determinado usuário no decorrer de um tempo ou comparando a usabilidade do produto entre um usuário experiente e outro inexperiente.

Um produto atenderá às individualidades, se tiver atributos que facilitem a adaptação às necessidades do usuário ao executar uma determinada tarefa. 


\section{Elza Maria Ferraz Barboza / Eny Marcelino de Almeida / Nathália Kneipp Sena}

A flexibilidade real de uso será alcançada por usuários diversos na execução de diferentes tarefas, medindo-se a usabilidade em contextos diferentes.

Qualquer componente do contexto de uso (usuário, equipamento tarefa, ambiente) pode ser manipulado para mudar a usabilidade de um produto.

Os web sites preencheram em mais de $50 \%$ de forma positiva os critérios da avaliação, à exceção do ministério $\mathrm{H}$, que teve um percentual maior de discrepâncias, como pode ser visualizado na figura 2. Concluiu-se, então, que os sites necessitam de revisão para maior adequação aos critérios ergonômicos, criando uma estratégia de fortalecimento de suas características e naquilo que lhes seja único na oferta de serviços.

\section{REFERÊNCIAS BIBLIOGRÁFICAS}

1. ALEXANDER, Janet E. \& TATE, Marsha Ann. Checklist for an informational web page. Disponível na URL http:// www2.widener.edu/wolfgram-Memorial-Library/inform.htm

2. ___ . Teaching critical evaluation skills for World Wide Web resources. Computer in Libraries, v.16, n. 10, p.49-54, 1996.

3. BRASIL. Governo Federal. Manual de uso de marca. Brasília, 1999.

4. EUROPEAN COMMUNITIES. European Comission. Public sector information: key resource for Europe (Green Paper on Public Sector Information in the Information Society). Luxembourg, 1999. 5. IBM. Guide to web style: quick reference. Disponível na URL http://www.sun.com/styleguide/tables

6. INSTONE, Keith. Site usability evaluation. Disponível na URL http:/ /style.webview.com/br/pub97/10/10/usability/index.html

7. INTERNATIONAL STANDARD ORGANISATION (ISO) Ergonomic requirements for office work with visual display terminals (VDTs). Part 10: Dialogue principles. Genève,1996. (ISO 9241. 10:1996).

8. — Part 11: Guidance on usability. Genève, 1998. (ISO 9241-11:1998).

9. —— Part 12: Presentation of information. Genève, 1998. (ISO 9241-12:1998)

10. LYNCH, P.J. \& HORTON, S. The Yale style manual. New Heaven, Yale University, 1997. Disponível na URL http:// info.med.yale.edu/caim/manual

11. Mc MURDO, George. Evaluating web information and design Journal of Information Science, v. 24, n.3, p.192-204, 1998.

12. NIELSEN, Jakob. How users read on the web. Disponível na URL http://www.useit.com/alertbox/9710a.html

13. - Ten mistakes in web design. Disponível na URL http:/ /useit.com/alertbox/9605.html

14. NUNES, Eny Marcelino de Almeida. Aplicação de métodos de avaliação ergonômica em interface de sistemas de recuperação de informação em bases de dados. Brasília, 1999. xi, 14p. Dissertação (Mestrado em Ciência da Informação) - Universidade de Brasília.

15. RIBEIRO, Milton. Planejamento visual gráfico. 7 ed. rev. e atualizada. Brasília, Linha Gráfica Editora, 1998. 500 p. Inclui ilustrações.

16. SHNEIDERMAN, Ben. Designing the user interface: strategies for effective human-computer interaction. 3.ed. Reading. Ma., Addison-Wesley, 1998. 638p.

17. SMITH, A. G. Testing the surf: criteria for evaluating Internet information resources. Disponível na URL http://info.lib.uh.edu/ $\mathrm{pr} / \mathrm{v} 8 / \mathrm{n} 3 / \mathrm{smit} 8 \mathrm{n} 3 . \mathrm{html}$ 
Web sites governamentais, uma esplanada à parte

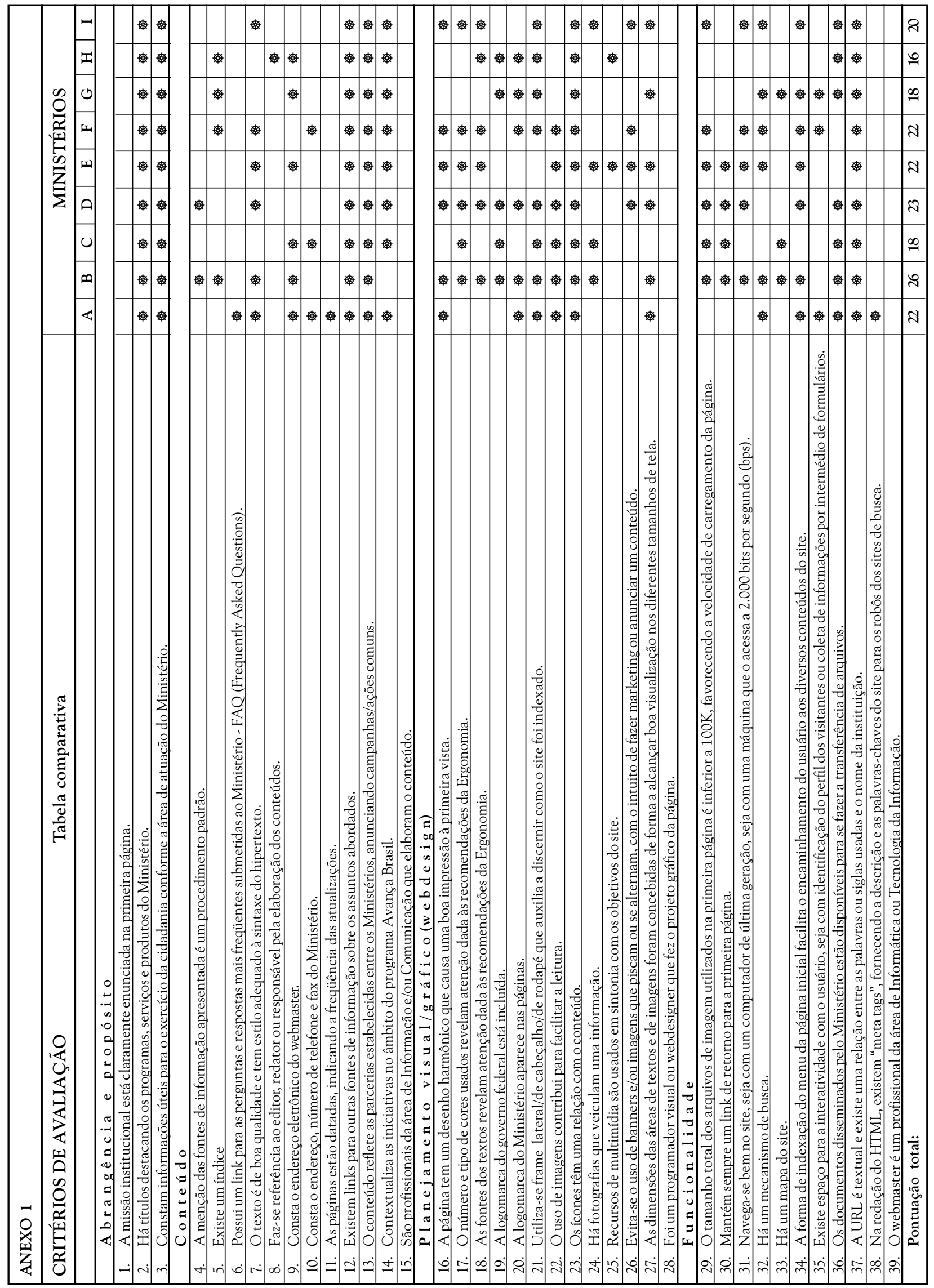

